\title{
DIFFERENTIAL DIAGNOSIS OF POLYARTHRITIS: PARACOCCIDIOIDOMYCOSIS
}

Gabriel Freitas de Campos (UFMT, Sinop, MT, Brasil), Heloisa Maria Lopes Scarinci (UFMT, Sinop, MT, Brasil), Fabiana de Castro Machado (UFMT, Sinop, MT, Brasil), Gabriel Ribeiro Leão Barroso (UFMT, Sinop, MT, Brasil), Allana Campos Alves (UFMT, Sinop, MT, Brasil), Diogo Rios de Avila (UFMT, sinop, MT, Brasil), Andressa Gabrielly Rodrigues beserra (UFMT, Sinop, MT, Brasil), Rodrigo Almeida de Medeiros (Patologista, Londriga, PR, Brasil), Flavio Fernandes Barboza (UFMT, Sinop, MT, Brasil)

\section{BACKGROUND}

Paracoccidioidomycosis (PCM) is a disease caused by the fungus Paracoccidioides brasiliensis, which infects the host upon reaching the upper airways. The course of the disease is characterized by acute and chronic phases. In addition to hepatic, splenic and lymphatic manifestations, there are often osteoarticular impairments, resulting from fungal proliferation or the patient's immune response. Therefore, in cases of arthritis in epidemiological areas susceptible to fungus, it is essential that PCM be the differential diagnosis of this disease.

\section{CASE REPORT}

A 57-year-old male patient had a clinical picture with diffuse pain, intense asthenia and proximal interphalangeal (PFI), metacarpophalangeal (MTC), and wrist polyarthritis for the last three years. He reported diffuse lesions on the skin, gingiva, tongue, palate and oropharynx ( figure1 and 2), suggestive of paracoccus infection, and was referred for biopsy of a mucosal lesion (figure3). After diagnosis of PCM, a treatment with 1 capsule of itraconazole every 12 hours was started. In the first month of medication, there was complete improvement of joint pain and the beginning of recovery of tegumentary lesions. The treatment was carried forward by an infectologist.

\section{CONCLUSION}

It is interesting to note that fungal diseases have, for the most part, monoarticular involvement characteristics linked to septic arthritis. However, as discussed before, a minor polyarthritis of joints was observed, in a reactional manner, caused by the patient's own immune response. Thus, the rheumatologist must always be aware of this type of reactional involvement in order to perform the differential diagnosis of polyarthritis. 